PatientSafety/InfectionControl/hh_monograph.htm. Accessed August 3, 2009.

2. Pittet D. Compliance with hand disinfection and its impact on hospitalacquired infections. J Hosp Infect 2001;48(Suppl A):S40-S46.

3. Haas JP, Larson EL. Measurement of compliance with hand hygiene. $J$ Hosp Infect 2007;66:6-14.

\section{Infection Prevention Education: Are We Neglecting It?}

To the Editor-Healthcare-associated infections pose a formidable challenge to the healthcare industry, with a significant impact on patient outcomes. ${ }^{1}$ Preventive measures such as hand hygiene are of paramount importance in reducing healthcare-associated infections, but despite the utility of this simple procedure, compliance rates are suboptimal at many healthcare institutions. ${ }^{2}$ Part of the reason for nonadherence to basic measures of infection prevention is lack of knowledge among physicians. ${ }^{3}$ Infection prevention education has the potential to be effective, but didactic teaching sessions specifically intended for physicians in training are limited. ${ }^{4} \mathrm{Few}$ studies have assessed what physicians in training know about infection prevention, and the existing evidence reveals that physicians lack sufficient knowledge about this topic. ${ }^{5-8}$ Moreover, the data in the medical literature tend to be more reflective of norms within the United Kingdom and other European countries than of norms identified within the United States. ${ }^{4-8}$ Notably, there are no specific educational guidelines set by the Accreditation Council for Graduate Medical Education, which cites a need for residents to "demonstrate knowledge of established and evolving biomedical, clinical, epidemiological, and social-behavioral sciences." This broad objective would encompass education about infection prevention. However, we are not aware of any structured curricula that residency programs in the United States have adopted to educate physicians about infection prevention. We therefore conducted a cross-sectional study to gather information about how internal medicine residency programs in the United States educate house staff on these principles.

There are 381 internal medicine residency training programs in the United States and its territories. Essential contact information with regard to the programs was obtained from the Fellowship and Residency Electronic Interactive Database. ${ }^{10}$ This was done after approval from our institutional review board. US internal medicine residency program directors were sent a cover letter with a survey and a preaddressed postcard. The program directors completed the form and returned it to us. In an effort to ensure anonymity, instructions were provided to mail the postcard separately.

The letter conveyed the intent of gathering information about the different ways residency programs educated house
TABLE. Compliance with Hand Hygiene, by Healthcare Job

\begin{tabular}{lcc}
\hline Job title & $\begin{array}{c}\text { No. of } \\
\text { observations }\end{array}$ & Compliance, \% \\
\hline Nurse & 25,234 & 87.4 \\
Physician & 4,511 & 66.3 \\
Radiology technician & 314 & 67.8 \\
Respiratory therapist & 829 & 87.5 \\
Physical therapist & 245 & 86.5 \\
Other & 1,267 & 81.7 \\
Total & 32,400 & 84.0 \\
\hline
\end{tabular}

staff about basic principles of infection prevention. Specifically, the letter stated that, for the purposes of this survey:

[T] he term 'Infection Prevention' generally encompasses (but is not strictly limited to) the following basic principles:

Hand Hygiene: Use of antibacterial soap and water or hand sanitizer before and after patient/environment contact,

Precautions: Types of precautions (ie, contact airborne, droplet isolation, etc), and

Multi-Drug Resistant Organisms: Understanding the significance of drug resistant organisms such as MRSA and VRE.

Commonly conceivable means of educating house staff were listed on the questionnaire (Table 1). The last option, "Other (please specify)," was kept open-ended to gather additional means of education on infection prevention. The survey was prepared by the investigators and reviewed by a variety of teaching physicians and a public health professional prior to distribution.

From the 381 internal medicine residency training programs (and their respective program directors) in the United States and its territories, we obtained responses to the survey from 158 program directors (41.4\%) within a 3-month period. No responses were obtained thereafter. Responses to the questionnaire survey have been tabulated (Table 1). Ad hoc responses within the "Other (please specify)" category were grouped on the basis of similar themes (not verbatim), including the following commonly conceivable means of educating house staff:

1. Activities occurring during clinical rotations (rounds on floor, morning report, intensive care rotation): 9 independent responses.

2. Incorporated into the agenda during resident meetings/conferences (meetings with faculty, non-core lectures, "continuous" reinforcement--not otherwise specified): 6 independent responses.

3. Captured by general hospital safety campaigns (Quality Improvement, Quality Assurance, preparation for The Joint Commission inspection): 6 independent responses.

4. Hand washing monitoring on floors providing direct feedback: 1 independent response.

There is increasing awareness of the importance of infection prevention in healthcare facilities. Although many states 
TABLE 1. Responses to the items in survey questionnaire

\begin{tabular}{lc}
\hline & $\begin{array}{c}\text { No. (\%) of } \\
\text { program directors } \\
\text { who responded } \\
(n=158)\end{array}$ \\
\hline Commonly conceivable means of educating house staff & \\
1. A general discussion integrated into introduction to hospital policies/safety proce- & $125(79.1)$ \\
dures during orientation for all new hospital employees & $122(77.2)$ \\
3. A dedicated lecture during orientation specific for incoming physicians in training & \\
tended for resident physicians & $90(56.9)$ \\
4. An obligatory rotation in Infectious Diseases & $72(45.5)$ \\
5. An elective (optional) rotation in Infectious Diseases & $83(52.5)$ \\
6. An online module dedicated to the fundamentals of infection prevention & $54(34.1)$ \\
7. Other (please specify): & $22(13.9)$ \\
\hline
\end{tabular}

have required the reporting of hospital-acquired infections, we feel that the initiative on the part of hospitals to optimally educate healthcare personnel is lacking. Low rates of hand hygiene across hospitals in the United States may be partially attributable to inadequate training of resident physicians. ${ }^{2}$ On the basis of the survey results, it appears that many programs (according to $79 \%$ of survey respondents) typically relegate the topic of infection prevention to a general lecture series for all new hospital employees. Physicians being taught infection prevention intended for all new hospital employees may dismiss the importance of these sessions. A significant number of internal medicine programs (according to $77 \%$ of survey respondents) rely on a dedicated lecture to new house staff, but outlines for subsequent reinforcement may not be well delineated. Even for those who are obligated to rotate in the infectious diseases department (ie, $45 \%$ of survey respondents), discussions regarding infection prevention may lack a well-defined, cohesive structure. A minority of survey respondents (ie, $34 \%$ ) reported of an online module for infection prevention.

Education of residents about infection prevention relies on the discretion of individual training programs. Although residency programs may incorporate the importance of infection prevention in the curricula for resident education, this may not translate into integration into daily clinical activities. If this important aspect of patient care and safety is to become an integral component of medical education, then standardized curricula for ongoing education should be developed.

Our study has certain limitations. Less than one-half of the surveyed residency program directors responded to the survey. Moreover, the survey responses were limited to physicians in training in internal medicine. It may be possible that some programs educate physicians in ways other than those listed in the questionnaire, and therefore an open-ended choice was incorporated, to which the response was low (ie, $13.9 \%$ of survey respondents). Despite an overall low-response rate, the results of the study provide a view of the methods of educating resident physicians in internal medicine about infection prevention in the United States.

\section{ACKNOWLEDGMENTS}

We thank Edward K. Chapnick, MD, and Michael A. Joseph, PhD, MPH, for their help with formulating the questionnaire and editing the manuscript. We also thank Ms Crystal Sinagra for preparing and mailing the surveys.

Potential conflicts of interest. All authors report no conflicts of interest relevant to this letter.

Andrew G. Sahud, MD; Nitin Bhanot, MD, MPH; Sunil Bhat, MD; Stacy Lane, DO; Rajinder Bajwa, MD

From the Division of Infectious Diseases (A.G.S, N.B., S.B., S.L.) and the Department of Internal Medicine (R.B.), Allegheny General Hospital, Pittsburgh, Pennsylvania.

Address reprint requests to Andrew G. Sahud, MD, Division of Infectious Diseases, Allegheny General Hospital, 320 East North Avenue, South Tower, Pittsburgh, PA 15212 (asahud@wpahs.org).

Infect Control Hosp Epidemiol 2010; 31:199-201

(C) 2009 by The Society for Healthcare Epidemiology of America. All rights reserved. 0899-823X/2010/3102-0019\$15.00. DOI: 10.1086/650381

\section{REFERENCES}

1. Klevens RM, Edwards JR, Richards CL Jr, et al. Estimating health careassociated infections and deaths in U.S. hospitals, 2002. Public Health Rep 2007:122:160-166.

2. Boyce JM, Pittet D. Guideline for hand hygiene in health-care settings: recommendations of the Healthcare Infection Control Practices Advisory Committee and the HICPAC/SHEA/APIC/IDSA Hand Hygiene Task Force. Infect Control Hosp Epidemiol 2002;23(12 suppl):S3-\$40.

3. Erasmus V, Brouwer W, van Beeck EF, et al. A qualitative exploration of reasons for poor hand hygiene among hospital workers: lack of positive role models and of convincing evidence that hand hygiene prevents crossinfection. Infect Control Hosp Epidemiol 2009;30:415-419.

4. Farrington $M$. Infection control education: how to make an impacttools for the job. J Hosp Infect 2007;65(suppl 2):128-132.

5. Mann CM, Wood A. How much do medical students know about infection control? J Hosp Infect 2006;64:366-370.

6. Sax H, Perneger T, Hugonnet S, Herrault P, Chraïti MN, Pittet D. Knowl- 
edge of standard and isolation precautions in a large teaching hospital. Infect Control Hosp Epidemiol 2005;26:298-304.

7. Brady RR, McDermott C, Gibb AP, Paterson-Brown S. Fact or infection: do surgical trainees know enough about infection control? Ann $R$ Coll Surg Engl 2008;90:647-650.

8. Tavolacci MP, Ladner J, Bailly L, Merle V, Pitrou I, Czernichow P. Prevention of nosocomial infection and standard precautions: knowledge and source of information among healthcare students. Infect Control Hosp Epidemiol 2008;29:642-647.
9. Accreditation Council for Graduate Medical Education (ACGME). Program director guide to the common program requirements. IV. Education program. http://www.acgme.org/acWebsite/navPages/ commonpr_documents/IVA5b_EducationalProgram_ACGMECom petencies_MedicalKnowledge_Documentation.pdf. Accessed July 26, 2009.

10. American Medical Association (AMA). FRIEDA online. http://www.ama -assn.org/ama/pub/education-careers/graduate-medical-education/freida -online.shtml. Accessed February 2, 2009. 